\title{
Polymorphism of CYP2D6, CYP2C19, CYP2C9 and CYP2C8 in the Faroese population
}

\section{Citation}

Halling, Jónrit, Maria S. Petersen, Per Damkier, Flemming Nielsen, Philippe Grandjean, Pál Weihe, Stefan Lundgren, Mia Sandberg Lundblad, and Kim Brøsen. 2005. "Polymorphism of CYP2D6, CYP2C19, CYP2C9 and CYP2C8 in the Faroese Population." European Journal of Clinical Pharmacology 61 (7) (July 16): 491-497. doi:10.1007/s00228-005-0938-1.

\section{Published Version}

doi:10.1007/s00228-005-0938-1

\section{Permanent link}

http://nrs.harvard.edu/urn-3:HUL.InstRepos:34786606

\section{Terms of Use}

This article was downloaded from Harvard University's DASH repository, and is made available under the terms and conditions applicable to Other Posted Material, as set forth at http:// nrs.harvard.edu/urn-3:HUL.InstRepos:dash.current.terms-of-use\#LAA

\section{Share Your Story}

The Harvard community has made this article openly available.

Please share how this access benefits you. Submit a story.

\section{Accessibility}




\section{POLYMORPHISM OF CYP2D6, CYP2C19, CYP2C9 AND CYP2C8 IN THE FAROESE POPULATION}

\section{Jónrit Halling1, Maria S. Petersen², Per Damkier ${ }^{3}$, Flemming Nielsen ${ }^{1,2}$, Philippe Grandjean², Pál Weihe ${ }^{4}$, Stefan Lundgren ${ }^{5}$, Mia Sandberg Lundblad ${ }^{5}$ and Kim Brøsen ${ }^{1}$}

\footnotetext{
${ }^{1}$ Institute of Public Health, Clinical Pharmacology, University of Southern Denmark, Winslovparken 19, 5000 Odense C, Denmark.

${ }^{2}$ Institute of Public Health, Enviromental Medicine, University of Southern Denmark, Winslovparken 17, 5000 Odense C, Denmark.

${ }^{3}$ Department KKA, Clinical Pharmacology, Odense University Hospital, Odense, Denmark

${ }^{4}$ The Faroese Hospital System, Department of Occupational and Public Health, Sigmundargota 5, 100 Tórshavn, Faroe Islands.

${ }^{5}$ Division of Clinical Pharmacology, Karolinska University Hospital Huddinge, Stockholm, Sweden.
}

\section{Correspondence}

Jónrit Halling, cand.pharm.

Institute of Public Health, Faculty of Health Sciences

Clinical Pharmacology

University of Southern Denmark

Winslovparken 19, DK-5000 Odense C, Denmark

Phone: (+45) 65503066, Fax (+45) 65916089

E-mail: jhalling@health.sdu.dk

Number of pages: 9

Number of tables: 7

Number of figures: 3

Informative title:

Phenotypes and genotypes for CYP2D6 and CYP2C19 and genotypes for CYP2C9 and CYP2C8 in the Faroese population 
Abstract Objective: The purpose of the study was to study the distribution of poor and extensive metabolizers of CYP2C19 and CYP2D6 and to genotype for CYP2C8 and CYP2C9 among 312 randomly selected Faroese.

Methods and Results: The participants were phenotyped for CYP2D6 with the use of sparteine. The distribution of the sparteine metabolic ratio (sparteine/didehydrosparteines) was bimodal, and $14.5 \%(n=44)(95 \%$ CI 10.7-18.9\%) of the subjects were phenotyped as poor metabolizers. The frequency of poor metabolizers was higher $\left(\mathrm{P}=0.0002 ; \chi^{2}\right.$ test) among the Faroese than in other European populations (7.4\%). Genotype analysis for the $C Y P 2 D 6^{*} 3, * 4, * 6$ and $* 9$ alleles were performed using real-time PCR (TaqMan $\left.{ }^{\circledR}\right)$, and we found 14.6\% ( $\left.\mathrm{n}=45\right)(95 \%$ CI 10.8-19.0\%) with deficient CYP2D6 genes $(* 3 / * 4, * 4 / * 4, * 4 * 6, * 6 / * 6)$ in the Faroese population.

The subjects were phenotyped for CYP2C19 with the use of mephenytoin and 10 subjects, i.e. 3.2\% (95\% CI 1.6-5.9\%) were phenotyped as poor metabolizers. Genotype analysis for the CYP2C19*2 and $* 3$ alleles was performed by PCR analysis and $2.9 \%(n=9)(95 \%$ CI $1.3-5.4 \%)$ of the Faroese were found to have a deficient $C Y P 2 C 19$ gene all explained by the $C Y P 2 C 19 * 2 / * 2$ genotype. The allele frequencies of the $C Y P 2 C 9 * 2$ and $C Y P 2 C 9 * 3$ alleles were $8.8 \%$ (95\% CI 6.7-11.4\%) and $5.3 \%$ (95\% CI 3.7-7.4\%), respectively, while the CYP2C8*3 allele frequency was $6.9 \%$ (95\% CI 5.0-9.2\%). Real-time PCR (TaqMan ${ }^{\circledR}$ ) was used for both $C Y P 2 C 9$ and CYP2C8 genotype analyses. Conclusion: The frequency of CYP2D6 poor metabolizers is two fold higher among the Faroese population compared to other Caucasians, while the frequencies of Faroese subjects with decreased CYP2C19, CYP2C8 and CYP2C9 enzyme activity are the same as seen in other Caucasian populations. A possible consequence might be a higher incidence of side effects among Faroese patients taking pharmaceuticals that are CYP2D6 substrates.

Keywords: CYP2D6, CYP2C19, CYP2C8, CYP2C9, Faroe Islands, polymorphism. 


\section{Introduction}

The polymorphisms of CYP2D6 and CYP2C19 are relatively well known, and more than 80 mutations of the CYP2D6 gene and about 15 mutations of the CYP2C19 gene have been described [1]. More than 75 drugs are metabolized by CYP2D6, including antidepressants, selective serotonin reuptake inhibitors and opioids [2]. CYP2C19 metabolizes more than 25 drugs including proton pump inbibitors and some antidepressants [3]. Populations in different environments and with different genetic backgrounds show interethnic differences in drug metabolism [4]. Geographical differences in the metabolism of sparteine (CYP2D6) and also S-mephenytoin (CYP2C19) are well known. The CYP2D6 poor metabolizers represent 5-10\% of Caucasians [5] and 0-2\% of African and Orientals [6],[7]. The frequency of CYP2C19 poor metabolizers varies from approximately 3\% in Caucasians and Africans to $13-23 \%$ of Orientals [4]. Genetic polymorphisms have also been identified for CYP2C8 that oxidizes drugs such as taxol, cerivastatin, as well as endobiotics such as retinoic acid and arachidonic acid [8]. The most frequent allele associated with defective metabolism is the CYP2C8*3 allele, which occurs with a frequency of $13 \%$ in Caucasians and $2 \%$ in Afro-Americans [9]. The polymorphic CYP2C9 enzyme is responsible for the metabolism of several commonly used drugs, including $S$-warfarin, phenytoin and the nonsteroidal antiinflammatory drugs [10]. The $C Y P 2 C 9 * 2$ allele has been found in $11-13 \%$ of Caucasians, $1-4 \%$ of Africans, while it is not present in Orientals [11]. A SNP linkage disequilibrium between the CYP2C8 and CYP2C9 genes has been reported. According to Yasar et al. 2002 [12], 96\% of the subjects with $C Y P 2 C 8 * 3$ alleles also carried $C Y P 2 C 9 * 2$ alleles, while $85 \%$ of the subjects genotyped as $C Y P 2 C 9 * 2$ also were genotyped as $C Y P 2 C 8 * 3$.

The Faroe Islands include 18 islands situated northwest of Scotland and halfway between Iceland and Norway.

The Faroese population derives mainly from Vikings of predominantly Norse extraction, who settled in the Faroe Islands in the 9th century [13],[14]. However, an influx of men and women from the British Isles, either as independent colonisers, or brought there by Vikings, may have contributed significantly to the current gene pool of the Faroese population [15]. It has been suggested that the Faroes were populated by Irish monks or hermits as early as 650 A.D. and they may have left before the Norse settlement [16]. 
Genetic studies of the Faroese population are limited, but increased incidence of diseases associated with specific gene mutations are known, presumably due to founder effects [17], isolation, inbreeding or simply genetic drift. Examples of diseases are glycogen storage disease type IIIA (GSD IIIA) [18], hereditary hemochromatosis HFE [19], cystic fibrosis CF [20], primary ciliary dyskinesia [17] and classical non-AIDS-related Kaposi's sarcoma [21].

According to the findings cited above it is likely that the Faroese population is of Nordic origin, but in some aspects genetically different from other Caucasian populations. Hence, we were interested in studying the activity of the important drug metabolising enzymes CYP2D6 and CYP2C19, as well as the occurrence of variant alleles within the $C Y P 2 D 6, C Y P 2 C 19, C Y P 2 C 9$ and $C Y P 2 C 8$ genes, among Faroese subjects.

\section{Methods}

\section{Subjects}

From the Faroese national register we received the names of 900 randomly selected Faroese individuals between 18 and 60 years, which was the inclusion criteria. Approximately one third was excluded based on the following criteria: concomitant medication, pregnancy or breastfeeding and allergy to medicine. One third refused to participate of various reasons. Hence three hundred and twelve healthy Faroese (144 females and 168 males) were recruited. The mean age of the participants was 39 years. All subjects consented to participate on the basis of verbal and written information in Faroese. The study was approved by the Faroese Ethics Committee.

Out of the 312 volunteers, eight individuals were excluded from the sparteine test: Two women were excluded from the phenotyping part because of uncertain pregnancy status, but blood samples were taken for genotype analysis. Further, the analysis of the urine from four persons showed that they had not ingested the sparteine capsule, even though they had collected urine. For two subjects the urine volume was not recorded and consequently these two persons were therefore excluded. In total, 304 persons were included in the CYP2D6 phenotype analysis.

The two possibly pregnant women, were also excluded from the mephenytoin test. Thereby, 310 persons were included in the CYP2C19 phenotype analysis.

For the CYP2D6, CYP2C19, CYP2C8 and CYP2C9 genotype analysis, one person was excluded because it was not possible to get a blood sample from him. He was however included in the 
phenotype analysis. Two samples could not be genotyped for CYP2D6 either due to homozygosity for the $C Y P 2 D 6 * 5$ allele or poor quality of DNA, and were excluded from the genotype analyses. Consequently, 311 samples were genotyped for CYP2C19, CYP2C8 and CYP2C9, and 309 for CYP2D6.

\section{Phenotyping}

After emptying the bladder the participants took an oral dose of $100 \mathrm{mg}$ racemic mephenytoin (Mesantoin! , Sandoz Pharmaceuticals Corporation, East Hanover, NJ) and $100 \mathrm{mg}$ sparteinesulphate-pentahydrate (The Central Pharmacy, Odense University Hospital, Denmark). They also received $200 \mathrm{mg}$ of caffeine at the same time due to participation in another study on CYP1A2. It has been demonstrated, that the simultaneous administration of low dose of these drugs does not influence the outcome of their respective metabolic indices [22],[23]. Urine was collected from $0 \mathrm{~h}$ to $12 \mathrm{~h}$ after dosing. The total volume was recorded, and aliquots of $2 \times 10 \mathrm{ml}$ were stored at $-80^{\circ} \mathrm{C}$ until analysis. Sparteine, 2,3- and 5,6- didehydrosparetine in urine (\% of dose) was assayed by gas chromatography [24]. The metabolic ratio (MR) was calculated as:

$\mathrm{MR}=$

$\%$ of dose sparteine

( $\%$ of dose 2,3-didehydrosparteine $+\%$ of dose 5,6-didehydrosparteine)

in the $12 \mathrm{~h}$ urine.

Individuals with a sparteine MR greater than 14 were classified as poor metabolizers (PMs).

Historically the antimode between poor and extensive metabolizers is 20 , but this is an arbitrary value and scientifically not better founded then for instance 14. Inspection of the data from the genotype analysis in this particular study encourages us to set an antimode of 14 instead of 20 . In this manner the phenotype results were analysed accordingly with respect to genotype accordance. Three subject with MR ratios below 20 (14.3, 14.5 and 18.9) had a CYP2D6 deficient genotype.

The ratio between $S$-and $R$-mephenytoin in the urine was determined using gas chromatography according to Wedlund et al. [25] as modified by Sanz et al. [26].

All urine samples with $\mathrm{S} / \mathrm{R}$ ratio $>0.5$ were reanalysed after acid treatment according to Tybring \& Bertilsson [27]. In extensive metabolizers the $S / R$ ratio increases to several times the original value, 
whereas it remains the same in true poor metabolizers. Subjects having S/R ratios $>1$, which did not increase significantly after acid treatment, were thus classified as poor metabolizers.

\section{Genotyping}

A $10 \mathrm{ml}$ blood sample was drawn in EDTA containing Vacutainer tubes (BD, Franklin Lakes, NJ), and the blood was immediately transferred to a DNA glass (Terumo Europe, Haasrode, Belgium) and kept frozen at $-80^{\circ} \mathrm{C}$ until extraction of DNA for PCR analysis. DNA was isolated by PUREGENE $^{\mathrm{T}}{ }^{\mathrm{M}}$ genomic DNA purification kit by Gentra Systems, Minnesota 55441, USA. Genotype analysis for the CYP2D6*3, *4, *6 and *9 alleles were performed by PCR before using the Taqman ${ }^{\circledR}$ technology. The realtime analysis was performed at the ABI PRISM 7700 Sequence Detection System equipped with the allelic discrimination module (software version 1.7; Applied Biosystems). Genotype analysis for the $C Y P 2 C 19 * 2$ and $* 3$ alleles was performed as described previously [28],[29]. Primers and probes for CYP2D6 and CYP2C19 were purchased from Applied Biosystems (Foster City, CA).

The samples were also genotyped for the $C Y P 2 C 9 * 2$ and $* 3$ alleles as well as the $C Y P 2 C 8 * 3$ allele. The method for $C Y P 2 C 8 * 3$ and $C Y P 2 C 9 * 3$ have previously been described [12]. For the CYP2C9*2 allele new primers and probes, specific for the CYP2C9 gene, were designed (table 3 and 5), using Primer Express 1.0 from Applied Biosystems, Invitrogen (Paisley, Scotland, UK).

Primers and probes used in this study are summarized in Table 1-3.

\section{Results}

Among 304 Faroese subject phenotyped with sparteine, 44 had an MR ratio above 14 and were assigned as poor metabolizers. Thus, the incidence of CYP2D6 poor metabolizers was $14.5 \%(95 \%$ CI 10.7-18.9\%). The frequency of poor metabolizers was 2 fold higher $\left(\mathrm{P}=0.0002 ; \chi^{2}\right.$ test $)$ among the Faroese compared with other European populations (7.4\%) [5].

The MR ratio in the Faroese ranged from 0.10 to 230 and the frequency distribution in extensive and poor metabolizers of sparteine is shown in Figure 2.

By genotype analysis the frequency of the CYP2D6*3, *4, *6 and *9 alleles was determined for 309 individuals and a high frequency of the CYP2D6*4 allele (33.4\%) (95\% CI 29.7-37.3\%) was 
observed. The frequency of $C Y P 2 D 6 * 1, * 3, * 6$ and $* 9$ was $62.0 \%(95 \%$ CI $57.6-65.4 \%), 0.2 \%(95 \%$ C I $0.004-0.9 \%), 1.9 \% \quad(95 \%$ CI $1.0-3.3 \%)$ and $0.8 \%$ (95\% CI $0.3-1.9 \%)$ respectively. The frequency of Faroese subjects carrying CYP2D6 deficient genes was found to be $14.6 \%$ ( $=45)$ (95\% CI 10.8-19.0\%).

Out of the 312 persons recruited, 304 persons were phenotyped for CYP2D6 and 44 of these were classified as poor metabolizers. 309 persons were genotyped for CYP2D6 and 45 carried a deficient gene.

Among 310 Faroese subjects phenotyped with mephenytoin, 18 individuals had an $\mathrm{S} / \mathrm{R}$ ratio $\geq 0.5$, and they were all clearly classified as poor or extensive metabolizers after acid treatment and reanalysis of the samples, and 10 were assigned as poor metabolizers having a $S / R$ ratio $\geq 1$. The prevalence of poor metabolizers of $S$-mephenytoin in the population studied was therefore $3.2 \%$ (95\% CI 1.6-5.9\%). Statistically, this frequency was not significantly different from other Europeans $\left(\mathrm{P}=0.80 ; \chi^{2}\right.$ test) [5] The $\mathrm{S} / \mathrm{R}$ ratio distribution in extensive and poor metabolizers of $S$ mephenytoin is presented in Figure 3.

Nine out of the ten poor metabolizers of CYP2C19, identified through the mephenytoin test, were by the genotype analysis found to be homozygous for the $C Y P 2 C 19 * 2$ mutation. The last one was genotyped as $C Y P 2 C 19^{*} 1 / * 2$. This person had a $\mathrm{S} / \mathrm{R}$ ratio of 1.18 before and 1.26 after acid treatment and were therefore by the phenotype analysis classified as poor metabolizer. The CYP2C19*3 mutation was not found in the Faroese population, and the frequency of subjects with CYP2C19 deficient genes was found to be $2.9 \%$ (95\% CI $1.35 .4 \%$ ).

The allele frequencies of $C Y P 2 C 9 * 1, * 2$ and $* 3$ and $C Y P 2 C 8 * 1$, *3 were $86.7 \%$ (95\% CI 83.789.2\%), 8.8\% (95\% CI 6.7-11.4\%), 5.3\% (95\% CI 3.7-7.4\%), 93.0 (95\% CI 90.8-95.0\%) and 6.9\% (95\% CI 5.0-9.2\%) respectively. This is in agreement with previous reported allele frequencies in other Caucasians [30].

95\% (95\% CI 84.2-99.4\%) of the subjects with CYP2C8*3 alleles also carried CYP2C9*2 alleles, while $75 \%(95 \%$ CI $61.0-85.3 \%)$ of the subjects having the $C Y P 2 C 9 * 2$ variant also carried CYP2C8*3 alleles.

The results of the CYP2D6, CYP2C19, CYP2C9 and CYP2C8 genotyping in the Faroese population are summarized in Table 4-7. 


\section{Discussion}

This study is the first to estimate the distribution of CYP2D6 and CYP2C19 poor and extensive metabolizers and the distribution of CYP2C8 and CYP2C9 genotypes in the Faroese population. The observed frequency of CYP2D6 poor metabolizers is about 14\% in Faroese subjects, which is about twice the frequency reported in other Caucasians populations. The reason for the high frequency of CYP2D6 poor metabolizers among Faroese is unknown but might be due to the geographical isolation of the Faroe Islands, giving rise to a genetically homogeneous population.

The frequency of CYP2D6 poor metabolizers found by the phenotype analysis $(14.5 \%)$ is slightly different from the frequency of subjects with CYP2D6 deficient genotypes found by the genotype analysis (14.6\%). There are different reasons for this finding but they can all be explained.

One of the two women, who did not ingest the sparteine capsule because of possible pregnancy, was genotyped as $C Y P 2 D 6^{*} 4 / * 4$. Two of the four subjects, where the urine analysis showed that they had not ingested the sparteine capsule, also had a CYP2D6 deficient genotype. Further 304 subjects were included in the CYP2D6 phenotype analysis while 309 were genotyped for CYP2D6. However we consider the result demonstrates a concordance between the frequencies found by the phenotype and genotype analysis.

The CYP2D6 polymorphism has been studied as a risk factor for Parkinson's disease (PD), and a higher frequency of CYP2D6 poor metabolizers among PD patients has been reported [31],[32]. The number of PD patients is relatively higher on the Faroe Islands comparired to other countries [33],[34],[35] and the frequency of CYP2D6 poor metabolizers is twice as high as in other Caucasians. Therefore there may be an association between these two facts.

Tricyclic antidepressants (TCA) are metabolized by CYP2D6, which also catalyses the metabolism of a number of other antidepressants [36],[37]. Poor metabolizer pheno- and genotype may result in very high plasma drug concentration and lead to side effects [38]. Hence, the high frequency of CYP2D6 poor metabolizers among Faroese presumably result in a respectively larger part of the population suffering from adverse effects when taking CYP2D6 substrates, especially TCA's than seen in other populations. 
As a consequence of the high frequency of CYP2D6 poor metabolizers, the response rate to analgesic treatment with tramadol is probably decreased in several Faroese patients. Experimental pain studies have showed reduced efficacy of tramadol in poor metabolizers [39],[40].

In conclusion the frequency of CYP2D6 poor metabolizers is twofold higher in the Faroese population compared to other Caucasians, while the frequencies of Faroese subjects with decreased CYP2C19, CYP2C8 and CYP2C9 enzyme activity are the same as seen in other Caucasian populations. Further studies of e.g. the association between PD and CYP2D6 poor metabolizers among Faroese are warranted. Attention to possible side effects of drug treatments in Faroese CYP2D6 poor metabolizers is needed.

\section{Acknowledgement}

This study was supported by "Apotekerfonden af 1991", and by grants from the Swedish Science Council, Medicine (00496).

The assistance of the employees at the Department of Occupational and Public Health in Tórshavn, Faroe Islands is highly appreciated.

2,3- didehydrosparteine and 5,6- didehydrosparteine were kindly donated by Michael Eichelbaum from Dr Margarete Fischer-Bosch Institute of Clinical Pharmacology in Stuttgart, Germany. 
1. http://www.imm.ki.se/cypalleles

2. Nebert DW, Russel DW (2002) Clinical importance of cytochromes P450. The Lancet 360:11551162.

3. Wedlund PJ (2000) The CYP2C19 Enzyme Polymorphism. Pharmacology 61:174-183.

4. Bertilsson L (1995) Geographical/interracial differences in polymorphic drug oxidation. Clin Pharmacokinet 29:192-209.

5. Alván G, Becthel P, Islius L, Gundert-Remy U (1990) Hydroxylation polymorphisms of debrisoquine and mephenytoin in European population. Eur J Clin Pharmacol 39:533-537.

6. Bertilsson L, Lou Y-Q, Du Y-L, Liu Y. Kuang T-Y Liao X-M, et al. (1992) Pronounced differences between native Chinese and Swedish populations in the polymorphic hydroxylation of debrisoquin and S-mephenytoin. Clin Pharmacol Ther 51:388-397.

7. Bathum L, Johansson I, Ingelman-Sundberg M, Hørder M, Brøsen K (1998) Ultrarapid metabolism of sparteine:frequency of alleles with duplicatted CYP2D6 genes in a Danish population as determined by restriction fragment length polymorphism and long polymerase chain reaction. Pharmacogenetics 8:119-123.

8. Schoch GA, Yano JK, Wester MR, Griffin KJ, Stout CD, Johnson EF (2004) Structure of human microsomal cytochrom P450 2C8. Evidence for a peripheral fatty acid binding site. J Biol Chem 279(10):9497-9503.

9. Dai D, Zeldin DC, Blaisdell JA, Chanas B, Coulter SJ, Ghanayem BI, Goldstein JA (2001) Polymorphism in human CYP2C8 decrease metabolism of the anticancer drug paclitaxel and acachidonic acid. Pharmacogenetics 11:597-607.

10. Tracy TS, Hutzler JM, Haining RL, Rettie AE, Hummel MA, Dickmann LJ (2002) Polymorphic variants $(C Y P 2 C 9 * 3$ and $C Y P 2 C 9 * 5)$ and the $\mathrm{F} 114 \mathrm{~L}$ active site mutation of CYP2C9: effect on atypical kinetic metabolism profiles. Drug Metab Dispos 30(4):385-390.

11. Goldstein JA (2001) Clinical relevance of genetic polymorphisms in the human CYP2C subfamily. Br J Clin Pharmacol 52:349-355.

12. Yasar U, Lundgren S, Eliasson E, Bennet A, Wiman B, De Faire U, Rane A (2002) Linkage between the CYP2C8 and CYP2C9 genetic polymorphism. Biochem Biophys Res Commun 299(1):25-28.

13. Debes HJ (1990) Føroya Søga 1. Føroya Skúlabókagrunnur, Tórshavn.

14. Young GVC (1979) From the Vikings to the reformation: a chronicle of the Faroe Islands up to 1538. Shearwater Press, Onchan, Isles of Man.

15. Jorgensen TH, Buttenschon HN, Wang AG, Als TD, Borglum AD, Ewald H (2004) The origin of the isolated population of the Faroe Islands investigated using Y chromosomal markers. Hum Genet 115(1):19-28.

16. Jóhansen J (1885) Studies in the vegetational history of the Faroe and Shetlands Islands. Føroya Fródskaparfelag, Tórshavn. 
17. Jeganathan D, Chodhari R, Meeks M, Færoe O, Smyth D, Nielsen K, Amirav I, Luder AS, Bidgaard H, Gqrdiner RM, Chung EMK, Mitchinson HM (2004) Loci for primary ciliary dyskinesia map to chromosome 16p12.1-12.2 and 15q13.1-15.1 in Faroe Islands and Israeli Druze genetics isolates. J Med Genet 41:233-240.

18. Santer R, Kinner M, Steuerwald U, Kjærgaard S, Skovby F, Simonsen H, Shaiu W-L, Chen T-T, Schneppenheim R, Schaub J (2001) Molecular genetic basis and prevalence of glycogen storage disease type IIIA in the Faroe Islands. Eur J Hum Gen 9:388-391.

19. Milman N, Steig T, Koefoed P, Pedersen P, Fenger K, Nielsen FC (2004) Frequency of the hemochromatosis HFE metations C282Y, H63D, and S65C in blood donors in the Faroe Isalnds. Ann Hematol 84(3):146-149.

20. Schwartz M, Sorensen N, Brandt NJ, Hogdall E, Holm T (1995) High incidence of cystic fibrosis on the Faroe Islands: a molecular and genealogical study. Hum Genet 95(6):703-706.

21. Hjalgrim H, Tulinius H, Dalberg J, Hardarson S, Frisch M, Melbye M (1998) High incidence of classical Kaposi's sarcoma in Iceland and the Faroe Islands. Br J Cancer 77(7):1190-1193.

22. Frye RF, Matzke GR, Adedoyin A, Porter JA, Branch RA (1997) Validation of the five-drug "Pittsburgh cocktail" approach for assessment of selective regulation of drug-metabolizing enzymes. Clin Pharmacol Ther 62(4):365-376

23. Damkier P, Hansen LL, Brosen K (1999) Effect of diclofenac, disulfiram, itraconazole, grapefruit juice and erythromycin on the pharmacokinetics of quinidine. Br J Clin Pharmacol 48(6):829-838

24. Vinks A, Inaba T, Otton SV, Kalow W (1982) Sparteine metabolism in Canadian Causcasians. Clin Pharmacol Ther 31:23-29.

25. Wedlund PJ, Sweetman BJ, McAllister CB, Branch RA (1984) Wilkinson GR. Direct enantionmeric resolution of mephenytoin and its $\mathrm{N}$-demethylated metabolite in plasma and blood using chiral capillary gas chromatogram. J Chromatogr 13;307:121-127.

26. Sanz EJ, Villén T, Alm C, Bertilsson L (1989) S-mephenytoin hydroxylation phenotypes in a swedish population determined after coadministration with debrisquine. Clin Pharmacol Ther 45:495-499.

27. Tybring G, Bertilsson L (1992) A methodological investigation on the estimation of the S-mephenytoin hydroxylation phenotype using the urinary S/R ratio. Pharmacogenetics 2:241-243.

28. De Morais SMF, Wilkinson GR, Blaisdell J, Meyer US, Nakamura K, Goldstein JA (1994) The major genetic defect responsible for the polymorphism of S-mephenytoin in humans. J Bio Chem 269:15419-15422.

29. De Morais SMF, Wilkinson GR, Blaisdell J, Meyer US, Nakamura K, Goldstein JA (1994) Identification of a new genetic defect responsible for the polymorphism of S-mephenytoin metabolism in Japanese. Mol Pharmacol 46:594-598.

30. Sandberg M, Johansson I, Christensen M, Rane A, Eliasson E (2004) The impact of CYP2C9 genetics and oral contraceptives on cytochrome P450 2C9 phenotype. Drug Metab Dispos 32(5):484-489 
31. McCann SJ, Pond SM, James KM, Le Couteur DG (1997) The association between polymorphisms in the cytochrome P-450 2D6 gene and Parkinson's disease: a case-control study and meta-analysis. J Neurol Sci 153(1):50-53.

32. Christensen PM, Gotzsche PC, Brosen K (1998) The sparteine/debrisoquine (CYP2D6) oxidation polymorphism and the risk of Parkinson's disease: a meta-analysis. Pharmacogenetics 8(6):473-479.

33. Tandberg E, Larsen JP, Nessler EG, Riise T, Aarli JA (1995) The epidemiology of Parkinson's disease in the county of Rogaland, Norway. Mov Disord 10(5):541-549.

34. Gudmundsson KR (1967) A clinical survey of parkinsonism in Iceland. Acta Neurol Scand 43:Suppl $33: 1-61$.

35. Wermuth L, Joensen P, Bunger N, Jeune B (1997) High prevalence of Parkinson's disease in the Faroe Islands. Neurology 49(2):426-432.

36. Eichelbaum M, Gross AS (1990) The genetic polymorphism of debrisoquine/sparteine metabolism-clinical aspects. Pharmacol Ther 46(3):377-394.

37. Bertilsson L, Dahl ML, Dalen P, Al-Shurbaji A (2002) Molecular genetics of CYP2D6: clinical elevance with focus on psychotropic drugs. Br J Clin Pharmacol 53(2):111-122.

38. Meyer UA, Amrein R, Balant LP, Bertilsson L, Eichelbaum M, Guentert TW, Henauer S, Jackson P, Laux G, Mikkelsen H, Peck C, Pollock BG, Priest R, Sjoqvist F, Delini-Stula A (1996)

Antidepressants and drug-metabolizing enzymes-expert group report. Acta Psychiatr Scand 93(2):71-79.

39. Stamer UM, Lehnen K, Hothker F, Bayerer B, Wolf S, Hoeft A, Stuber F (2003) Impact of CYP2D6 genotype on postoperative tramadol analgesia. Pain 105(1-2):231-238.

40. Poulsen L, Arendt-Nielsen L, Brosen K, Sindrup SH (1996) The hypoalgesic effect of tramadol in relation to CYP2D6. Clin Pharmacol Ther 60(6):636-644. 
Table 1. Sequence of oligonucleotide CYP2D6 primers and probes used in this study

Table 2. Sequence of oligonucleotide CYP2C19 primers used in this study

Table 3. Sequence of oligonucleotide $C Y P 2 C 9 * 2$ primers and probes used in this study

Table 4: Allele frequencies (A) and genotype frequencies (B) of CYP2D6 with 95\% confidence intervals in the Faroese population.

Table 5: Allele frequencies (A) and genotype frequencies (B) of CYP2C19 with $95 \%$ confidence intervals in the Faroese population.

Table 6: Allele frequencies (A) and genotype frequencies (B) of $C Y P 2 C 9$ with $95 \%$ confidence intervals in the Faroese population.

Table 7: Allele frequencies (A) and genotype frequencies (B) of CYP2C 8 with $95 \%$ confidence intervals in the Faroese population. 
Table 1.

Sequence of oligonucleotide CYP2D6 primers used in this study

\begin{tabular}{|c|c|}
\hline Primers & Sequence $5^{\prime} \rightarrow 3^{\prime}$ \\
\hline$\overline{\mathrm{CYP} 1}$ & att tcc cag gaa tcc \\
\hline CYP4 & ccg gec ctg aca ctc ctt ct \\
\hline$C Y P 2 D 6 * 3$ sense & tcc tga ccc agc tgg atg a \\
\hline$C Y P 2 D 6 * 3$ antisense & ctt ctc cat ctc tgc cag gaa \\
\hline CYP2D6*4 sense & cga cce ctt acc cge atc \\
\hline$C Y P 2 D 6 * 4$ antisense & ctc acg get ttg tcc aag aga \\
\hline CYP2D6*6 sense & ctt ggg cet ggg caa ga \\
\hline$C Y P 2 D 6^{*} 6$ antisense & agg gca gca caa agg ca \\
\hline CYP $2 D 6^{*} 9$ sense & gag acc tga ctg agg cet tce $\mathrm{t}$ \\
\hline$C Y P 2 D 6 * 9$ antisense & tca ttc ctc ctg gga cge t \\
\hline
\end{tabular}

Sequence of oligonucleotide CYP2D6 probes used in this study

\begin{tabular}{|c|c|}
\hline Probes & Sequence $5^{\prime} \rightarrow 3^{\prime}$ \\
\hline$\overline{C Y P 2 D 6 * 3 \mathrm{wtMGB}}$ & FAM- tca tcc tgt gct cag $\mathrm{tt}-\mathrm{MGB}$ \\
\hline$C Y P 2 D 6 * 3$ mutMGB & VIC- tca tcc gtg ctc agt $t-M G B$ \\
\hline$C Y P 2 D 6^{*} 4 \mathrm{wt}$ & FAM- acc ccc agg acg cec ctt $t$-tamra \\
\hline$C Y P 2 D 6 * 4$ mut & JOE- acc ccc aag acg cec ctt tc-tamra \\
\hline CYP2D6*6 wtMGB & FAM- cgg tca ccc act gc-MGB \\
\hline$C Y P 2 D 6 * 6$ mutMGB & VIC- $\operatorname{cgg}$ tca ccc $\operatorname{ctg} \mathrm{c}-\mathrm{MGB}$ \\
\hline$C Y P 2 D 6 * 9$ wtMGB & FAM- tct cac ctt ctc cat ct-MGB \\
\hline$C Y P 2 D 6 * 9$ mutMGB & VIC- tct cac ctc cat ctc-MGB \\
\hline
\end{tabular}


Table 2.

Sequence of oligonucleotide CYP2C19 primers used in this study

\begin{tabular}{ll}
\hline Primers & Sequence $5^{\prime} \rightarrow 3^{\prime}$ \\
\hline MEP1 & aat tac aac cag agc ttg gc \\
MEP2 & tat cac tt cca taa aag caa g \\
MEP3 & tat tat tat ctg tta act aat atg a \\
MEP4 & act tca ggg ctt ggt caa ta \\
\hline
\end{tabular}


Table 3.

Sequence of specific oligonucleotide primers and MGB-TaqMan ${ }^{\circledR}$ probes used for the discrimination of the CYP2C $9 * 2$ alleles.

\begin{tabular}{|c|c|}
\hline Primers & ce $5^{\prime} \rightarrow 3^{\prime}$ \\
\hline Forward primer $\left(C Y P 2 C 9^{*} 2\right)$ & caa tgg aaa gaa atg gaa gga gat \\
\hline Reverse primer $(C Y P 2 C 9 * 2)$ & aag ata gta gtc cag taa ggt cag tga tat $g$ \\
\hline Probe (for discrimination of $C Y P 2 C 9^{*} 1$ ) & ttg aac acG gtc ctc \\
\hline Probe (for discrimination of $C Y P 2 C 9 * 2$ ) & $\operatorname{ttg}$ aac acAa gtc ctc a \\
\hline
\end{tabular}

The discrimination between $C Y P 2 C 9 * 1$ and $C Y P 2 C 9 * 3$ has been described elsewhere (Yasar et al., Biochem Biophys Res Commun. 2002 Nov 22;299(1):25-8). 
Table 4: Allele frequencies (A) and genotype frequencies (B) of CYP2D6 with $95 \%$ confidence intervals in the Faroese population.

\section{A}

Variant allele

Frequency

$95 \%$ confidence interval

$\begin{array}{lll}\text { CYP2D6*1 } & 0.616 & 0.576-0.654 \\ \text { CYP2D6*3 } & 0.002 & 0.00004-0.009 \\ \text { CYP2D6*4 } & 0.334 & 0.297-0.373 \\ \text { CYP2D6*6 } & 0.019 & 0.010-0.033 \\ \text { CYP2D6*9 } & 0.008 & 0.003-0.019\end{array}$

B

\section{Genotype}

Frequency

$95 \%$ confidence interval

CYP2D $6 * 1 / 1$ (EM)

CYP $2 D 6 * 1 / 4$ (EM)

CYP $2 D 6^{*} 1 / * 6$ (EM)

CYP $2 D 6 * 1 / * 9$ (EM)

CYP $2 D 6 * 4 / * 9$ (EM)

$C Y P 2 D 6 * 3 / * 4(\mathrm{PM})$

CYP $2 D 6 * 4 / * 4(\mathrm{PM})$

CYP $2 D 6 * 4 / * 6(\mathrm{PM})$

CYP2D6*6/*6 (PM)
0.418

0.395

0.019

0.009

0.006

0.032

0.125

0.013

0.032
$0.363-0.475$

$0.341-0.452$

$0.007-0.042$

$0.002-0.028$

$0.0008-0.023$

$0.00008-0.018$

$0.090-0.167$

$0.004-0.032$

$0.0008-0.018$ 
Table 5: Allele frequencies (A) and genotype frequencies (B) of CYP2C19 with $95 \%$ confidence intervals in the Faroese population.

\section{A}

Variant allele

Frequency

$95 \%$ confidence interval

$\begin{array}{lcc}C Y P 2 C 19 * 1 & 0.818 & 0.786-0.848 \\ \text { CYP2C19*2 } & 0.188 & 0.158-0.221 \\ \text { CYP2C19*3 } & 0 & \end{array}$

$\mathrm{B}$

Genotype

Frequency

$95 \%$ confidence interval

$\begin{array}{lll}C Y P 2 C 19 * 1 / * 1(\mathrm{EM}) & 0.662 & 0.607-0.715 \\ C Y P 2 C 19 * 1 / * 2(\mathrm{EM}) & 0.312 & 0.261-0.367 \\ C Y P 2 C 19 * 2 / * 2(\mathrm{PM}) & 0.032 & 0.016-0.058\end{array}$


Table 6: Allele frequencies (A) and genotype frequencies (B) of CYP2C9 with $95 \%$ confidence intervals in the Faroese population.

\section{A}

Variant allele

Frequency

$95 \%$ confidence interval

$\begin{array}{lcc}C Y P 2 C 9 * 1 & 0.867 & 0.837-0.892 \\ C Y P 2 C 9 * 2 & 0.088 & 0.067-0.114 \\ C Y P 2 C 9 * 3 & 0.053 & 0.037-0.074\end{array}$

B

Genotype

Frequency

$95 \%$ confidence interval

$\begin{array}{lcc}C Y P 2 C 9 * 1 / * 1 & 0.733 & 0.680-0.781 \\ C Y P 2 C 9 * 1 / 2 & 0.177 & 0.136-0.224 \\ C Y P 2 C 9 * 1 / * 3 & 0.106 & 0.074-0.146 \\ C Y P 2 C 9 * 2 / * 3 & 0.016 & 0.005-0.037\end{array}$


Table 7: Allele frequencies (A) and genotype frequencies (B) of CYP2C8 with $95 \%$ confidence intervals in the Faroese population.

\section{A}

Variant allele

Frequency

$95 \%$ confidence interval

$\begin{array}{lll}\text { CYP } 2 C 8 * 1 & 0.930 & 0.908-0.950 \\ \text { CYP } 2 C 8 * 3 & 0.069 & 0.050-0.092\end{array}$

B

Genotype

Frequency

$95 \%$ confidence interval

CYP $2 C 8 * 1 / * 1$

0.862

CYP $2 C 8 * 1 / 3$

0.138

$0.818-0.898$ 


\section{Legend to figures}

Figure 1. The position of the Faroe Islands

Figure 2. The distribution of sparteine metabolic ratios (MR) in 304 Faroese

Figure 3. The distribution of $S-$ and R-mephenytoin ratios (S/R) in 310 Faroese 


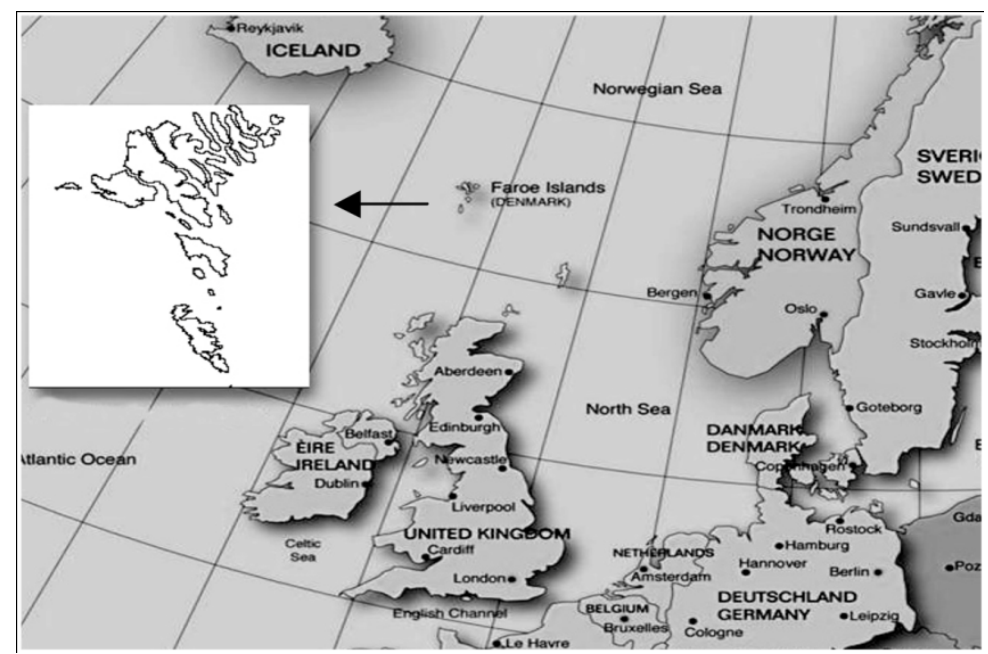

Figure 1. The position of the Faroe Islands 


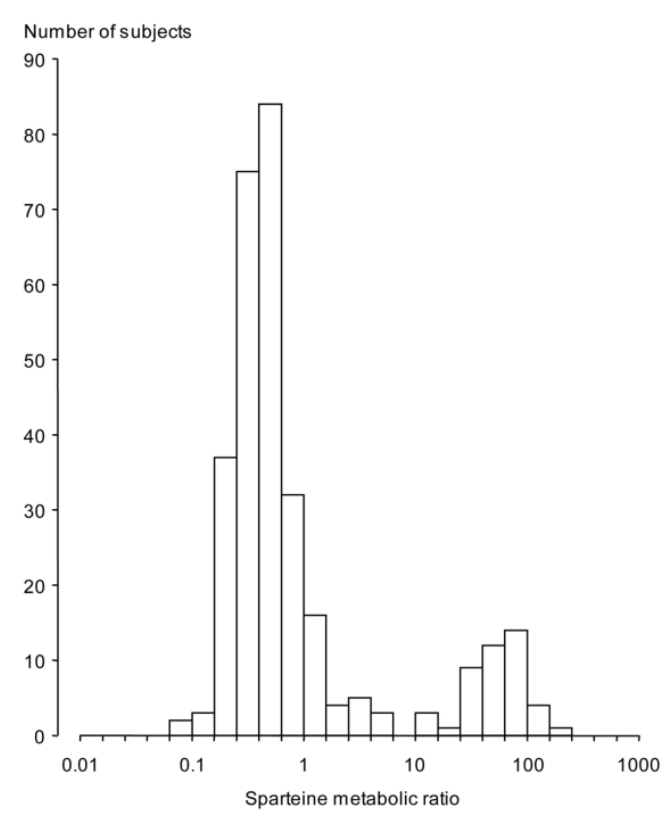

Figure 2. The distribution of sparteine metabolic ratios (MR) in 304 Faroese 


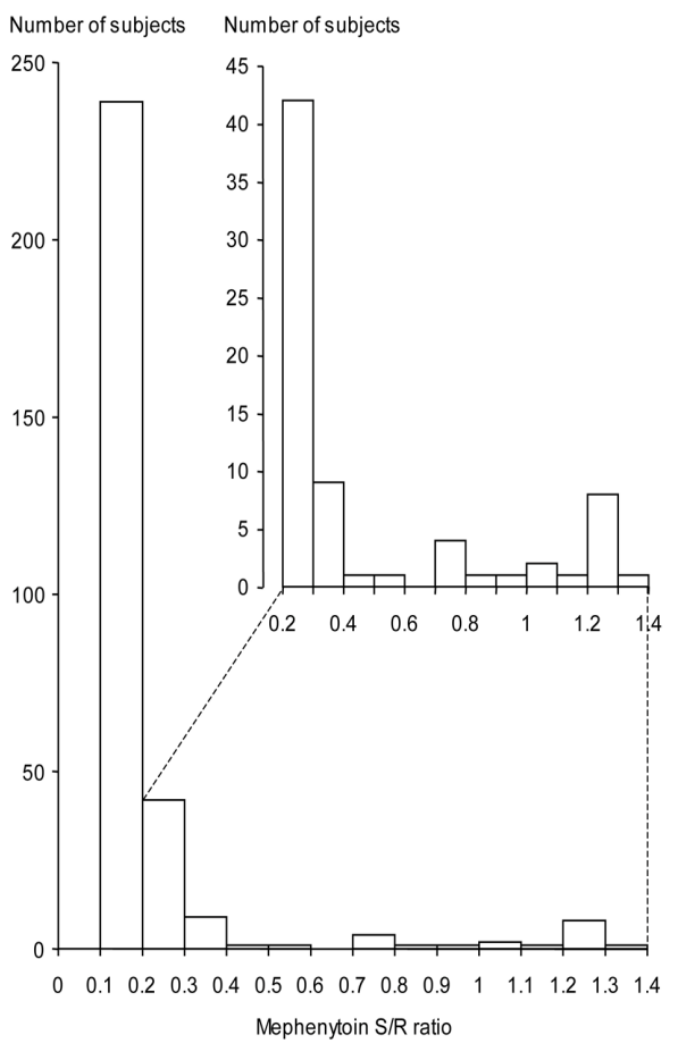

Figure 3. The distribution of S- and R-mephenytoin ratios (S/R) in 310 Faroese 